\title{
PENGARUH PEMBERIAN SEDIAAN CURCUMA DALAM SUSU DAN EMULSI TERHADAP PARAMETER FARMAKOKINETIKA PARASETAMOL
}

\author{
THE EFFECT OF CURCUMA IN EMULSION AND MILK \\ PREPARATION ON PARAMETER OF PHARMACOKINETICS \\ OF PARACETAMOL
}

\author{
Anjar Mahardian Kusuma, Wiranti Sri Rahayu, Siti Maryati, \\ Rini Afini Sobarani
}

Fakultas Farmasi Universitas Muhammadiyah Purwokerto

Email: anjarmahardian@gmail.com

\begin{abstract}
ABSTRAK
Penggunaan lebih dari satu macam obat dapat menimbulkan terjadinya interaksi. Pemberian multivitamin dan susu yang mengandung kurkumin, apabila diberikan dengan parasetamol secara bersamaan dimungkinkan dapat menimbulkan interaksi yang dapat berpengaruh terhadap parameter farmakokinetika parasetamol. Penelitian ini dilakukan dengan tujuan untuk mengetahui pengaruh pemberian curcuma emulsi dan susu curcuma yang mengandung kurkumin terhadap parameter farmakokinetika parasetamol pada tikus jantan wistar. Jenis metode penelitian yang digunakan yaitu jenis eksperimental dengan rancangan penelitian posttest only control group design dan metode analisis data yang digunakan adalah one way anova. Parameter farmakokinetika pada tiap kelompok mengalami perubahan. Nilai $C p_{\max }$ untuk kelompok I dengan pemberian parasetamol peroral dosis $150 \mathrm{mg} / \mathrm{kgBB}$ yaitu 4,129 $\mu \mathrm{g} / \mathrm{ml}$, kelompok II dan III dengan pemberian parasetamol dosis 150 $\mathrm{mg} / \mathrm{kgBB}$ dan curcuma emulsi dosis $0,9 \mathrm{mg} / \mathrm{kgBB}$ dan $1,8 \mathrm{mg} / \mathrm{kgBB}$ yaitu $3,904 \mu \mathrm{g} / \mathrm{ml}$ dan $3,894 \mu \mathrm{g} / \mathrm{ml}$, pada kelompok IV dan $\mathrm{V}$ dengan pemberian parasetamol dosis $150 \mathrm{mg} / \mathrm{kgBB}$ dan susu curcuma dosis $0,9 \mathrm{mg} / \mathrm{kgBB}$ dan $1,35 \mathrm{mg} / \mathrm{kgBB}$ yaitu $3,942 \mu \mathrm{g} / \mathrm{ml}$ dan $3,916 \mu \mathrm{g} / \mathrm{ml}$. Nilai klirens mengalami penurunan, yaitu pada kelompok I $88 \mathrm{ml} /$ menit, pada pemberian curcuma emulsi kelompok II dan III $87 \mathrm{ml} / \mathrm{menit}$ dan $84,8 \mathrm{ml} / \mathrm{menit}$, pada kelompok IV dan $\mathrm{V}$ dengan pemberian susu curcuma yaitu $87 \mathrm{ml} / \mathrm{menit}$ dan 85,2 $\mathrm{ml} /$ menit. Penurunan klirens menyebabkan terjadinya peningkatan nilai $A U C$ kelompok II, III, IV dan V. Hasil secara statistika menunjukkan perbedaan yang tidak signifikan $(p>0.05)$.
\end{abstract}

Kata kunci: curcuma emulsi, susu curcuma, parasetamol, interaksi. 


\section{ABSTRACT}

The use of more than one medicine may emerge to the interaction. Curcumin present in the multivitamin and in the milk, however, in the same time with paracetamol addition may create interaction that influence parameter of pharmacokinetic paracetamol. The aim of this research was to reveal the effect of curcuma emulsion and curcuma milk that contains curcumin to the parameter of pharmacokinetic paracetamol on Wistar male rats. The method of this research was experimental with "Posttest only control group design" and "one way anova" as the method of data analysis. Pharmacokinetic parameters in each group made some changes. Cpmax value in group I through oral paracetamol $150 \mathrm{mg} / \mathrm{kgBW}$ dosage was 4,129 $\mu \mathrm{g} / \mathrm{ml}$, group II and III with paracetamol $150 \mathrm{mg} / \mathrm{kgBW}$ dosage and curcuma emulsion $0,9 \mathrm{mg} / \mathrm{kgBW}$ dosage and $1,8 \mathrm{mg} / \mathrm{kgBW}$ dosage was 3,904 $\mu \mathrm{g} / \mathrm{ml}$ and 3,894 $\mu \mathrm{g} / \mathrm{ml}$, group IV and $V$ with paracetamol $150 \mathrm{mg} / \mathrm{kgBW}$ dosage and curcuma milk 0,9 $\mathrm{mg} / \mathrm{kgBW}$ dosage and 1,35 $\mathrm{mg} / \mathrm{kgBW}$ dosage was 3,942 $\mu \mathrm{g} / \mathrm{ml}$ and 3,916 $\mu \mathrm{g} / \mathrm{ml}$. Clirens value was declining, which lied in group I was $88 \mathrm{ml} / \mathrm{minutes}$ while group II and III with curcuma emulsion $87 \mathrm{ml} / \mathrm{minutes}$ and 84,8 $\mathrm{ml} /$ minutes, group $\mathrm{IV}$ and $V$ with curcuma milk was $87 \mathrm{ml} / \mathrm{minutes}$ and 85,2 $\mathrm{ml} /$ minutes. It influenced to the increasing of AUC value in group II,III, IV and $V$. In statistic result showed insignificant differences ( $p>0.05)$.

Key words: curcuma emulsion, curcuma milk, paracetamol, interaction.

\section{PENDAHULUAN}

Parasetamol dimetabolisme
oleh enzim mikrosom hati.

Sebagian parasetamol dikonjugasi dengan asam glukuronat dan sebagian kecil lainnya dengan asam sulfat (Wilmana dan Gan, 2008). Bila jalur glukuronidasi dan sulfatasi jenuh, maka akan terjadi peningkatan jumlah NAPQI $(\mathrm{N}$ Asetil-p-benzoquinon) melalui jalur oksidasi oleh sitokrom P450. NAPQI akan cepat dieliminasi dengan dikonjugasi oleh glutathion dan akan diubah menjadi asam merkapturat yang kemudian di ekskresikan melalui urin. Bila dosis parasetamol berlebih, maka jumlah glutathion pada sel hati akan habis, sehingga jumlah NAPQI yang tinggi akan berikatan dengan sel makromolekul dalam hati yang akan menyebabkan efek hepatotoksik (Goodman dan Gilman, 2006).

Kurkumin pertama kali disintesis oleh Pabon (1964) dengan material awal vanillin, asetilaseton dan borat anhidrat. Kurkumin makin popular secara internasional dan banyak diteliti para ilmuwan. Kurkumin dan beberapa turunannya antara lain mempunyai efek sebagai antiinflamasi, antikoagulan, antibakteri dan antioksidan (Oetari 
et al., 1997).

Pemberian multivitamin dan susu yang mengandung kurkumin apabila diberikan dengan parasetamol secara bersamaan dimungkinkan dapat menimbulkan interaksi. Interaksi kurkumin dan parasetamol diduga karena adanya penghambatan daur katalis P450 1A1 oleh kurkumin (Donatus, 1994), dimana enzim mikrosom hati berperan dalam metabolisme parasetamol (Wilmana \& Gan, 2008).

Berdasarkan pertimbangan di atas, perlu dilakukan penelitian yang mengkaji interaksi antara kurkumin yang terkandung dalam suatu sediaan seperti curcuma emulsi dan susu curcuma dengan parasetamol ditinjau dari parameter farmakokinetika parasetamol pada tikus jantan wistar terkait dengan penghambatan sitokrom P450 1A1 oleh kurkumin.

\section{METODE PENELITIAN}

Bahan yang digunakan pada penelitian ini adalah parasetamol baku (PT. Brataco), etilendiamin tetraasetat (Merck), kalium dihidrogen fosfat (Merck), natrium hidroksida (Merck), methanol (Merck), natrium carboxymetilselulosa (PT. Brataco), asetonitril (merck), aquabidestilata pro injeksi (Otsuka), sampel curcuma emulsi dan sampel susu curcuma. Subjek uji yang digunakan pada penelitian ini adalah tikus putih jantan wistar dengan berat badan sekitar $200 \mathrm{~g}( \pm 10 \%)$, umur sekitar 2-3 bulan dari kandang hewan percobaan Fakultas Farmasi Universitas Muhammadiyah Purwokerto.

Alat yang digunakan pada penelitian ini adalah seperangkat alat kromatografi cair kinerja tinggi (Shimadzu LC-10 A VP) yang menggunakan detektor UVVis SPD 10A, shimadzu system controller SCL-10A, dan Rheodyne loop injector. Kolom KCKT : Shimpack CLC-ODS; panjang $25 \mathrm{~cm}$, diameter 4,6 mm, ukuran partikel 5 $\mu \mathrm{m}$. Kertas whatman, penyaring vakum/tekanan beserta saringan berpori $0,45 \mu \mathrm{m}$, neraca analitis (Shimadzu ${ }^{\circledR}$ AY 220), pH meter (Metrohm), sonikator (Branson 1510), jarum suntik ujung tumpul, holder tikus, pisau bedah, vortex, sentrifugator.

Jalannya penelitian meliputi hewan uji dibagi menjadi 5 kelompok, masing-masing kelompok terdiri dari 5 ekor tikus. Kelompok I (kontrol) diberikan parasetamol secara peroral dengan dosis $150 \mathrm{mg} / \mathrm{kgBB}$. Kelompok II diberikan parasetamol secara peroral dengan dosis 150 $\mathrm{mg} / \mathrm{kgBB}$ dan curcuma emulsi secara peroral dengan dosis 0,9 $\mathrm{mg} / \mathrm{kgBB}$, Kelompok III diberikan parasetamol secara peroral dengan dosis $150 \mathrm{mg} / \mathrm{kgBB}$ dan curcuma emulsi secara peroral dengan dosis 
1,8 $\mathrm{mg} / \mathrm{kgBB}, \quad$ Kelompok IV diberikan parasetamol secara peroral dengan dosis $150 \mathrm{mg} / \mathrm{kgBB}$ dan susu curcuma secara peroral dengan dosis $0,9 \mathrm{mg} / \mathrm{kgBB}$, Kelompok V diberikan parasetamol secara peroral dengan dosis $150 \mathrm{mg} / \mathrm{kgBB}$ dan susu curcuma dosis 1,35 $\mathrm{mg} / \mathrm{kgBB}$. Setelah diberi perlakuan, darah dicuplik $0,5 \mathrm{ml}$ dari vena lateralis ekor pada menit ke-5, 15, 30, 60, 90, 120, 150, 180. Sampel kemudian ditambah EDTA 1\% 0,25 ml dan asetonitril sebanyak 0,75 $\mathrm{ml}$, lalu di vortex dan di sentrifugasi, kemudian supernatan diambil dan ditetapkan kadar parasetamol utuh dengan KCKT. Fase gerak yang digunakan adalah dapar fosfat $\mathrm{pH} 7,8$ dan methanol (90:10) (Wahyono, 2006). Kadar parasetamol dalam plasma darah dihitung berdasarkan kurva baku yang diperoleh. Parameter farmakokinetika yang dihitung antara lain t1/2eliminasi, Ka, Kel, tmax, Cpmax, AUC dan Klirens (Cl) berdasarkan data kadar parasetamol dalam plasma darah lawan waktu yang diperoleh pada masing- masing kelompok.

\section{HASIL DAN PEMBAHASAN}

Pada gambar 1, dengan adanya perlakuan curcuma emulsi dosis $0,9 \mathrm{mg} / \mathrm{kgBB}$ dan $\quad 1,8$ $\mathrm{mg} / \mathrm{kgBB}$, dan perlakuan susu curcuma dosis $0,9 \mathrm{mg} / \mathrm{kgBB}$ dan $1,35 \mathrm{mg} / \mathrm{kgBB}$ menunjukkan tidak mempengaruhi profil kurva farmakokinetika parasetamol dalam darah. Gambar 1 menggambarkan kurva hubungan kadar parasetamol dalam darah terhadap waktu setelah pemberian parasetamol dosis $150 \mathrm{mg} / \mathrm{kgBB}$ peroral (Kelompok I), pemberian parasetamol dosis $150 \mathrm{mg} / \mathrm{kgBB}$ peroral dan curcuma emulsi dosis 0,9 $\mathrm{mg} / \mathrm{kgBB}$ peroral (Kelompok II) , pemberian parasetamol dosis $150 \mathrm{mg} / \mathrm{kgBB}$ peroral dan curcuma emulsi dosis $1,8 \quad \mathrm{mg} / \mathrm{kgBB}$ peroral (Kelompok III), pemberian parasetamol dosis 150 $\mathrm{mg} / \mathrm{kgBB}$ peroral dan susu curcuma dosis $\quad 0,9 \quad \mathrm{mg} / \mathrm{kgBB} \quad$ peroral (Kelompok IV) dan pemberian parasetamol dosis $150 \mathrm{mg} / \mathrm{kgBB}$ peroral dan susu curcuma dosis 1,35 $\mathrm{mg} / \mathrm{kgBB}$ peroral (Kelompok V) pada tikus jantan $(\mathrm{N}=5)$. 
$\log \mathrm{Cp}$ $(\mu \mathrm{g} / \mathrm{ml})$

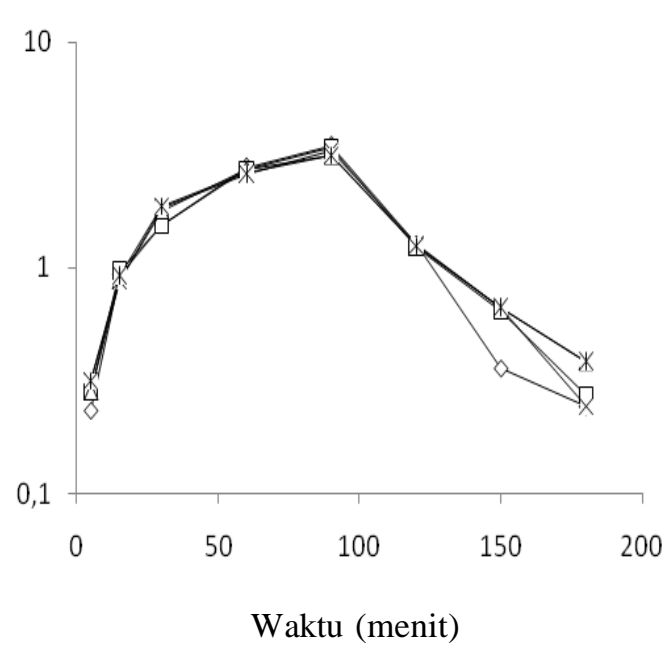

Concentration PCT in plasma

$\neg$ (Cp) group I (PCT 150 $\mathrm{mg} / \mathrm{kgBM}$ p.o

Concentration PCT in plasm

$\rightarrow$ (Cp) group $\|$ (PCT 150 $\mathrm{mg} / \mathrm{kgBW}$ and Curcuma emulsion 0.9 mg/kgBMp.o Concentration PCT in plasma

$\rightarrow$ (Cp) group III (PCT 150 $\mathrm{mg} / \mathrm{kgBW}$ and Curcuma emulsion $1.8 \mathrm{mg} / \mathrm{kgBW}$ p.o

$-x-$ Concentration PCT in plasma (Cp) group IV (PCT 150 mg/kgBW and curcuma milk 0.9 mg $/ \mathrm{kgBM}$ p.o

- * Concentration PCT in plasma (Cp) group $V$ (PCT 150 $\mathrm{mg} / \mathrm{kgBW}$ and curcuma milk 1.35 mgikgBW) p.o

Gambar 1 Kurva hubungan kadar parasetamol dalam darah terhadap waktu

Data nilai parameter-parameter farmakokinetika kelompok I, II, III, IV dan V dapatdilihat pada tabel I. Nilai parameter farmakokinetika parasetamol dalam darah terhadap waktu setelah pemberian parasetamol oral $150 \mathrm{mg} / \mathrm{kgBB}$ (kelompok I), pemberian parasetamol dosis $150 \mathrm{mg} / \mathrm{kgBB}$ peroral dan curcuma emulsi dosis $0,9 \mathrm{mg} / \mathrm{kgBB}$ peroral (kelompok II), pemberian parasetamol dosis $150 \mathrm{mg} / \mathrm{kgBB}$ peroral dan curcuma emulsi dosis $1,8 \mathrm{mg} / \mathrm{kgBB}$ peroral (kelompok III), pemberian parasetamol dosis $150 \mathrm{mg} / \mathrm{kgBB}$ peroral dan susu curcuma dosis 0,9 $\mathrm{mg} / \mathrm{kgBB}$ peroral (Kelompok IV) dan pemberian parasetamol dosis $150 \mathrm{mg} / \mathrm{kgBB}$ peroral dan susu curcuma dosis 1,35 $\mathrm{mg} / \mathrm{kgBB}$ peroral (Kelompok V) pada tikus jantan $(\mathrm{N}=5)$.

Nilai $\mathrm{t}_{\max }$ pada pemberian parasetamol dosis $150 \mathrm{mg} / \mathrm{kgBB}$ secara peroral tanpa perlakuan curcuma emulsi dan susu curcuma 30,273 menit, kemudian berubah menjadi 31,312 menit dan 31,346 menit setelah diberi perlakuan curcuma emulsi dosis $0,9 \mathrm{mg} / \mathrm{kgBB}$ dan $\quad 1,8 \quad \mathrm{mg} / \mathrm{kgBB}, \quad$ setelah pemberian susu curcuma dosis 0,9 $\mathrm{mg} / \mathrm{kgBB}$ dan $1,35 \mathrm{mg} / \mathrm{kgBB}$ berubah menjadi 30,940 menit dan 30,993 menit. Demikian juga untuk parameter $\mathrm{Cp}_{\text {max }}$ dan klirens (Cl) pada pemberian curcuma emulsi (Kelompok II dan III) dan pemberian susu curcuma (Kelompok IV dan V) mengalami penurunan, yaitu untuk $\mathrm{Cp}_{\text {max }}$ pada kelompok I dengan pemberian parasetamol dosis $150 \mathrm{mg} / \mathrm{kgBB}$ tanpa perlakuan curcuma emulsi dan susu curcuma yaitu $4,129 \mu \mathrm{g} / \mathrm{ml}$, pada kelompok II dan III dengan perlakuan curcuma emulsi dosis $0,9 \mathrm{mg} / \mathrm{kgBB}$ dan 1,8 $\mathrm{mg} / \mathrm{kgBB}$ yaitu $3,904 \mu \mathrm{g} / \mathrm{ml}$ dan 3,894 $\mu \mathrm{g} / \mathrm{ml}$, pada kelompok IV 
dan $\mathrm{V}$ dengan pemberian susu curcuma dosis $0,9 \mathrm{mg} / \mathrm{kgBB}$ dan $1,35 \mathrm{mg} / \mathrm{kgBB}$ yaitu $3,942 \mu \mathrm{g} / \mathrm{ml}$ dan 3,916 $\mu \mathrm{g} / \mathrm{ml}$. Untuk klirens pada kelompok I dengan pemberian parasetamol dosis $150 \mathrm{mg} / \mathrm{kgBB}$ tanpa perlakuan curcuma emulsi dan susu curcuma yaitu 88 $\mathrm{ml} /$ menit, pada kelompok II dan III dengan pemberian curcuma emulsi dosis $0,9 \quad \mathrm{mg} / \mathrm{kgBB}$ dan 1,8 $\mathrm{mg} / \mathrm{kgBB}$ mengalami penurunan yaitu $87 \mathrm{ml} /$ menit dan $84,8 \mathrm{ml} / \mathrm{menit}$, pada Kelompok IV dan V dengan pemberian susu curcuma dosis 0,9 $\mathrm{mg} / \mathrm{kgBB}$ dan $1,35 \mathrm{mg} / \mathrm{kgBB}$ mengalami penurunan pula yaitu 87 $\mathrm{ml} / \mathrm{menit}$ dan $85,2 \mathrm{ml} / \mathrm{menit}$. Adanya penurunan klirens menyebabkan terjadinya peningkatan nilai $A U C$ pada kelompok II dan III dengan pemberian curcuma emulsi dosis 0,9 $\mathrm{mg} / \mathrm{kgBB}$ dan $1,8 \mathrm{mg} / \mathrm{kgBB}$, yaitu 299,046 $\mu \mathrm{g} . \mathrm{menit} / \mathrm{ml}$ berubah menjadi 304,501 $\mu$ g.menit/ml dan 307,821 $\quad \mu \mathrm{g} . \mathrm{menit} / \mathrm{ml}$, pada Kelompok IV dan V dengan pemberian susu curcuma dengan dosis $0,9 \mathrm{mg} / \mathrm{kgBB}$ dan 1,35 $\mathrm{mg} / \mathrm{kgBB} \quad$ yaitu 299,046 $\mu \mathrm{g} . \mathrm{menit} / \mathrm{ml}$ berubah menjadi 302,907 $\mu$ g.menit/ml dan 309,027 $\mu \mathrm{g} . \mathrm{menit} / \mathrm{ml}$.

Perubahan parameter farmakokinetika parasetamol seperti $\mathrm{t}_{1 / 2 \text { eliminasi }}, \mathrm{K}_{\mathrm{a}}, \mathrm{K}_{\mathrm{el}}, \mathrm{t}_{\max }, \mathrm{Cp}_{\max }, A U C$ dan $\mathrm{Cl}$ secara statistika dengan menggunakan One Way ANOVA menunjukkan tidak ada perbedaan yang signifikan $(p>0,05)$. Perbedaan yang tidak signifikan $(p>0,05)$.

Tabel I : Harga parameter famakokinetika parasetamol dalam darah terhadap waktu

\begin{tabular}{|c|c|c|c|c|c|}
\hline \multirow{2}{*}{ Parameter } & \multicolumn{5}{|c|}{ Kelompok } \\
\hline & I & II & III & IV & $\mathrm{V}$ \\
\hline$t_{1 / 2 \text { eliminasi (menit) }}$ & 25,415 & 26,388 & 26,678 & 26,298 & 26,582 \\
\hline $\mathrm{Ka}\left(\right.$ menit $\left.^{-1}\right)$ & 0,042 & 0,037 & 0,044 & 0,036 & 0,041 \\
\hline $\operatorname{Kel}\left(\right.$ menit $\left.^{-1}\right)$ & 0,027 & 0,027 & 0,026 & 0,027 & 0,026 \\
\hline $\mathrm{t}_{\max }$ (menit) & 30,273 & 31,312 & 31,346 & 30,940 & 30,993 \\
\hline $\mathrm{Cp}_{\max }(\mu \mathrm{g} / \mathrm{ml})$ & 4,129 & 3,904 & 3,894 & 3,942 & 3,916 \\
\hline AUC ( $\mu \mathrm{g} \cdot \mathrm{menit} / \mathrm{ml})$ & 299,046 & 304,501 & 307,821 & 302,907 & 309,027 \\
\hline $\mathrm{Cl}$ (ml/menit) & 88 & 87 & 84,8 & 87 & 85,2 \\
\hline
\end{tabular}


Perbedaan yang tidak signifikan diduga karena enzim sitokrom P450 yang dihambat hanya sitokrom P450 1A1 dan enzim sitokrom P450 jenis lain tidak dihambat oleh kurkumin, dimana menurut Donatus (1994), interaksi kurkumin dan parasetamol diduga karena penghambatan daur katalis P450 1A1 oleh kurkumin.

\section{KESIMPULAN}

Pemberian curcuma emulsi dengan dosis $0,9 \mathrm{mg} / \mathrm{kgBB}$ dan $1,8 \mathrm{mg} / \mathrm{kgBB}$ dan pemberian susu curcuma dengan dosis $0,9 \mathrm{mg} / \mathrm{kgBB}$ dan 1,35 $\mathrm{mg} / \mathrm{kgBB}$ bersamaan dengan parasetamol dengan dosis $150 \mathrm{mg} / \mathrm{kgBB}$ secara per oral tidak mempengaruhi parameter farmakokinetika parasetamol pada tikus jantan wistar $(p>0,05)$.

\section{DAFTAR PUSTAKA}

Donatus, I.A., 1994, Antaraksi Kurkumin dan Parasetamol, Kajian terhadap Aspek Farmakologi dan Toksikologi Biotransformasi Parasetamol, Disertasi, Universitas Gadjah Mada, Yogyakarta.

Goodman dan Gilman's, 2008, Manual of Pharmacology and Therapeutics, McGraw-Hill Companies,Inc, United States.

Oetari, R.A., Suwaldi, M., Sugiyanto, Samhoedi, R., Vermeulen, N.P.E., 1997, Efek Hambatan Kurkumin (Bis(4-Hidroksi-3-Metoksifenil)1,6- Heptdadiien-3,5-Dion) dan Bis-(4-Metoksifenil)-1,6-
Heptadien-3,5- Dion Terhadap Aktivitas Sitokrom P450 Hati Tikus. Majalah Farmasi Indonesia, 8(1) : 24-33.

Wahyono, D, Hakim, A.R., 2006, Pengaruh praperlakuan pentagamavunon-0 terhadap profil farmakokinetika parasetamol pada tikus jantan wistar, Majalah Farmasi Indonesia, 17(4) : $194-198$.

Wilmana, P.F., Gan, S., 2008, Analgesik-Antipiretik Analgesik Anti-Inflamasi Nonsteroid dan Obat Gangguan Sendi Lainnya, Jakarta: Balai Penerbit FKUI : 238. 